\title{
Protein Tyrosine Phosphatase 1B Inhibitory Activity of Amentoflavone and Its Cellular Effect on Tyrosine Phosphorylation of Insulin Receptors
}

\author{
MinKyun NA, Kyung Ah Kıм, Hyuncheol Oн, ${ }^{1)}$ Bo Yeon Kıм, Won Keun Oн, and Jong Seog AнN* \\ Korea Research Institute of Bioscience and Biotechnology (KRIBB); 52 Eoun-dong, Yuseong-gu, Daejeon 305-806, Korea. \\ Received October 3, 2005; accepted September 26, 2006
}

\begin{abstract}
Inhibition of protein tyrosine phosphatase 1B (PTP1B) has been proposed as a strategy for the treatment of type 2 diabetes and obesity. Bioassay-guided fractionation of $\mathrm{MeOH}$ extract of Selaginella tamariscina (Selaginellaceae) afforded a PTP1B inhibitory compound, amentoflavone. The compound inhibited PTP1B with an IC I0 $_{5}$ value of $7.3 \pm 0.5 \mu \mathrm{M}$. Kinetic study suggested that amentoflavone is a non-competitive inhibitor of PTP1B, with a $K_{\mathrm{i}}$ value of $5.2 \mu \mathrm{M}$. Treatment of 32D cells overexpressing the insulin receptor (IR) with amentoflavone resulted in a dose-dependent increase in tyrosine phosphorylation of IR. These results indicate that amentoflavone may enhance insulin-induced intracellular signaling possibly through inhibition of PTP1B activity.
\end{abstract}

Key words protein tyrosine phosphatase 1B; Selaginella tamariscina; Selaginellaceae; amentoflavone; non-competitive inhibitor; tyrosine phosphorylation of insulin receptor

Insulin binding to the insulin receptor (IR) results in autophosphorylation on specific tyrosine residues, which in turn further activates the receptor tyrosine kinase and provides binding sites for the recruitment and subsequent phosphorylation of signaling proteins such as insulin receptor substrate (IRS) $1-4 .^{2,3)}$ Phosphorylated IRS activate several signaling cascades that mediate the biological effects of insulin including glucose uptake and glycogen synthesis. ${ }^{2,3}$ Protein tyrosine phosphatases (PTPs) catalyze the dephosphorylation of tyrosyl-phosphorylated proteins and are believed important negative regulators of insulin signaling. ${ }^{2,3}$ Although several PTPs such as PTP- $\alpha$, leukocyte antigen-related tyrosine phosphatase (LAR), and SH2-domain-containing phosphotyrosine phosphatase (SHP2) have been implicated in the regulation of insulin signaling, there is substantial evidence supporting PTP1B as the critical PTP controlling the insulin signaling pathway. ${ }^{2,3)}$ PTP1B can interact with and dephosphorylate activated IR as well as IRS proteins. $^{2,3)}$ Its overexpression has been shown to inhibit the IR signaling cascade and increased expression of PTP1B occurs in insulin-resistant states. ${ }^{4)}$ Furthermore, recent genetic evidence has shown that PTP1B gene variants are associated with changes in insulin sensitivity. ${ }^{5)}$ As with the insulin signaling pathway, the leptin signaling pathway can be attenuated by PTPs and there is compelling evidence that PTP1B is also involved in this process. ${ }^{2,3)}$ Therefore, it has been suggested that compounds that reduce PTP1B activity or expression levels could not only be used for the treatment of type 2 diabetes but also obesity. Although there have been a number of reports on the design and development of synthetic PTP1B inhibitors, ${ }^{2,6}$ there are only a few reports on PTP1B inhibitors derived from plants. ${ }^{7}$

In our continuing search for PTP1B inhibitors derived from plants, a $\mathrm{MeOH}$ extract of whole plants of Selaginella tamariscina (Selaginellaceae), which have been used to treat infectious diseases and malignant tumors, ${ }^{8)}$ was found to inhibit PTP1B activity $(>70 \%$ inhibition at $30 \mu \mathrm{g} / \mathrm{ml})$. Further fractionation of the $\mathrm{MeOH}$ extract as guided by in vitro PTP1B inhibitory assay afforded an active biflavonoid, amentoflavone (Fig. 1). Although amentoflavone has been reported to possess various pharmacological activities such as antioxidant, ${ }^{9)}$ anti-HIV, ${ }^{10)}$ anti-phospholipase $\mathrm{C} \gamma 1,{ }^{11)}$ and vasorelaxant effects, ${ }^{12)}$ there has been no study with regard to its inhibitory activity against PTP1B. In this study, we investigated the inhibitory effect of amentoflavone on PTP1B and confirmed its cellular effect on IR phosphorylation.

\section{MATERIALS AND METHODS}

Plant Material Whole plants of $S$. tamariscina were purchased from a local market in Daejeon, Korea. A voucher specimen (No. 005-041) has been deposited in our laboratory, KRIBB.

Extraction and Isolation Dried whole plants of $S$. tamariscina $(1 \mathrm{~kg})$ were extracted with $\mathrm{MeOH}(31)$ at $50^{\circ} \mathrm{C}$. The $\mathrm{MeOH}$ extract $(50.5 \mathrm{~g})$ was suspended in $\mathrm{H}_{2} \mathrm{O}$ and partitioned with hexane, EtOAc, and $\mathrm{BuOH}$, sequentially. The EtOAc-soluble fraction showed PTP1B inhibitory activity ( $>70 \%$ inhibition at $30 \mu \mathrm{g} / \mathrm{ml})$. The EtOAc-soluble fraction $(12 \mathrm{~g})$ was chromatographed over YMC gel $(4.5 \times 25 \mathrm{~cm}$; $150 \mu \mathrm{m}$ particle size) using a stepwise gradient of $\mathrm{MeOH}-$ $\mathrm{H}_{2} \mathrm{O}$ (from 0 to $100 \%$ with $20 \%$ increments; $500 \mathrm{ml}$ for each step), to yield five fractions (Fr. 1-Fr. 5). Of these, Fr. 5 showed the most potent PTP1B inhibitory activity (81\% inhibition at $10 \mu \mathrm{g} / \mathrm{ml}$ ). Fr. 5 (eluted with $100 \% \mathrm{MeOH}, 4.1 \mathrm{~g}$ ) was further purified over a silica gel column $(4.5 \times 25 \mathrm{~cm}$; $15-40 \mu \mathrm{m}$ particle size) chromatography eluting with a gradient from 0 to $100 \% \mathrm{CH}_{2} \mathrm{Cl}_{2}$ in $\mathrm{MeOH}$, to yield seventeen subfractions (Fr. 5-1-5-17). Fr. 5-10 (eluted with 91\% $\mathrm{CH}_{2} \mathrm{Cl}_{2}$ in $\mathrm{MeOH}$ ) was identified as an active principle

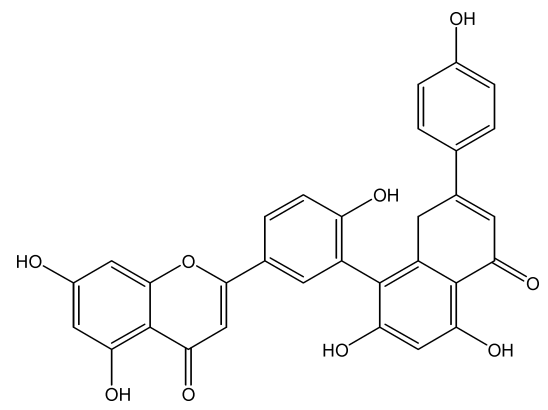

Fig. 1. Chemical Structure of Amentoflavone 
$\left\{450 \mathrm{mg},[\alpha]_{\mathrm{D}}+9^{\circ}(c=1.0, \mathrm{EtOH})\right\}$. The structure of the active compound was identified as amentoflavone by analyses of MS and ${ }^{1} \mathrm{H}$ - and ${ }^{13} \mathrm{C}$-NMR data, along with comparison of these data with those of published values. ${ }^{13)}$

Enzyme Assays and Inhibition Kinetics PTP1B, dualspecificity protein tyrosine phosphatase (VHR) and protein serine/threonine phosphatase (PP1) enzyme activities were measured using $p$-nitrophenyl phosphate ( $p$ NPP) as described previously. ${ }^{14)}$ In the kinetic analysis, the reaction mixture consisting of five different concentrations of $p$ NPP $(1.0,2.0,4.0,8.0 \mathrm{~mm})$ was used as PTP1B substrate in the absence or presence of amentoflavone. The MichaelisMenten constant $\left(K_{\mathrm{m}}\right)$ and maximum velocity $\left(V_{\max }\right)$ of PTP1B were determined by Lineweaver-Burk and EadieHofstee plots using a GraphPad Prism ${ }^{\circledR} 4$ program (GraphPad Software Inc., U.S.A.).

Tyrosine Phosphorylation of IR in 32D Cells Tyrosine phosphorylation levels of IR were measured using 32D cells overexpressing IR as described previously. ${ }^{15-17)}$ 32D cells cultured at near confluence were incubated with a range of concentrations of test compound for $60 \mathrm{~min}$ followed by treatment with or without $10 \mathrm{~nm}$ insulin for $10 \mathrm{~min}$. The cells were washed with cold PBS and pelleted by centrifugation at $3000 \boldsymbol{g}$ then resuspended in lysis buffer $(10 \mathrm{~mm}$ Tris- $\mathrm{HCl}, \mathrm{pH}$ 7.4, $150 \mathrm{~mm} \mathrm{NaCl}, 1 \%$ Triton X-100, 1 mм EDTA, 0.1\% SDS supplemented with Calbiochem ${ }^{\circledR}$ protease inhibitor cocktail set III and the following phosphatase inhibitors: $100 \mathrm{~mm} \mathrm{NaF}$, $2 \mathrm{~mm} \mathrm{Na} \mathrm{VO}_{4}, 30 \mathrm{~mm}$ sodium pyrophosphate, $1 \mathrm{~mm}$ ammonium molybdate, and $2 \mathrm{~mm}$ EGTA). The cell lysates ( $80 \mu \mathrm{g}$ protein) were subjected to SDS-PAGE then transferred to nitrocellulose membrane and followed by western blot with anti-pTyr (G410) antibodies (Upstate, U.S.A.). The bands of $\mathrm{IRb}(97 \mathrm{kDa})$ were confirmed by western blot with anti-IRb antibodies (Santa Cruz Biotechnology, U.S.A.). DMSO $(0.1 \%)$ and sodium vanadate $(10 \mu \mathrm{M})$ were used as negative and positive controls, respectively.

Statistical Analysis Results are expressed as mean \pm S.D. Differences between groups were examined for statistical significance using Student's $t$-test (GraphPad Prism ${ }^{\circledR} 4$ program). $p<0.05$ denoted the presence of a statistically significant difference.

\section{RESULTS AND DISCUSSION}

Recent evidence suggests a key role for PTPs in the control of insulin signaling and metabolism. ${ }^{2,3)}$ Of the PTPs, PTP1B appears an attractive therapeutic target because PTP1B levels in muscles and adipose tissues correlate with the degree of insulin resistance in subjects with diabetes and obesity. ${ }^{2,3)}$ Furthermore, recent genetic evidence has supported the idea that PTP1B inhibitors could be potential agents for the treatment of type 2 diabetes mellitus and obesity. $^{2,5)}$

As part of our ongoing search for natural PTP1B inhibitors from plants, the whole plants of $S$. tamariscina (Selaginellaceae) were chosen for detailed investigation, since the $\mathrm{MeOH}$ extract was found to inhibit PTP1B at $30 \mu \mathrm{g} / \mathrm{ml}$. Bioassay-guided fractionation of the active extract afforded a PTP1B-inhibitory compound, amentoflavone. As shown in Table 1, amentoflavone inhibited PTP1B activity in a dosedependent manner with an $\mathrm{IC}_{50}$ value of $7.3 \pm 0.5 \mu \mathrm{M}$. A
Table 1. Comparison of the Inhibitory Activity of Amentoflavone Isolated from $S$. tamariscina against PTP1B, VHR and PP1

\begin{tabular}{lccc}
\hline \hline \multirow{3}{*}{ Compounds } & \multicolumn{3}{c}{$\mathrm{IC}_{50}(\mu \mathrm{M})^{a)}$} \\
\cline { 2 - 4 } & PTP1B & VHR & PP1 \\
\hline Amentoflavone & $7.3 \pm 0.5$ & $>100$ & $>100$ \\
RK-682 $^{b)}$ & $4.5 \pm 0.5$ & $10.2 \pm 1.2$ & $>100$ \\
\hline
\end{tabular}

a) $\mathrm{IC}_{50}$ values were determined by regression analyses and expressed as mean \pm S.D. of three replicates. b) Positive control. ${ }^{17)}$

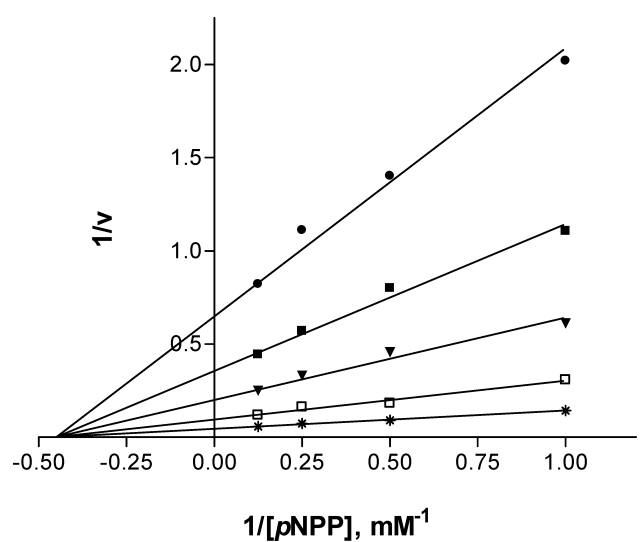

Fig. 2. A Lineweaver-Burk Plot of the Inhibitory Effect of Amentoflavone on PTP1B-Catalyzed Hydrolysis of $p$ NPP

Data are expressed as mean initial velocity for $n=3$ replicates at each substrate con-

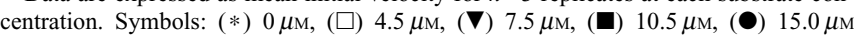
amentoflavone.

known phosphatase inhibitor, RK-682 $\left(\mathrm{IC}_{50}=4.5 \pm 0.5 \mu \mathrm{M}\right)$, was used as a positive control ${ }^{18)}$ in this assay. In addition, amentoflavone was tested for its inhibitory effects on other types of protein phosphatases, and it was shown that the compound has no inhibitory effects toward VHR and PP1 at levels $\leq 100 \mu \mathrm{M}$ (Table 1$)$. This suggests that amentoflavone has some degree of specific inhibitory activity against PTP1B. To elucidate the inhibition mode of amentoflavone on the activity of PTP1B, a kinetic analysis was performed with different concentrations of substrate. As shown in Fig. 2 , the mechanism of inhibition by the compound was determined using a Lineweaver-Burk plot. When $p$ NPP was used as substrate, amentoflavone decreased the $V_{\max }$ value but did not alter the $K_{\mathrm{m}}$ value of PTP1B (Fig. 2). Thus amentoflavone was determined as a non-competitive inhibitor with a $K_{\mathrm{i}}$ value of $5.2 \mu \mathrm{M}$. This result suggests that amentoflavone may bind to the enzyme-substrate complex or interact with an allosteric site distinct from the active site of the enzyme. $^{15)}$ Because PTP1B is an intracellular enzyme, potential PTP1B inhibitors need to have cellular activity. ${ }^{2)}$ Further to identify whether amentoflavone could inhibit PTP1B in cells and thus increase the tyrosine phosphorylation of the IR, we tested the compound using $32 \mathrm{D}$ cells overexpressing IR. ${ }^{19)}$ As shown in Fig. 3, tyrosine phosphorylation of IR was observed with insulin treatment (lane 3). Furthermore, tyrosine phosphorylation levels increased by 10.3 -fold in the presence of $10 \mu \mathrm{M}$ sodium vanadate, a general tyrosine phosphatase inhibitor (lane 4). ${ }^{20)}$ Treatment of the cells with amentoflavone resulted in a dose-dependent increase of insulin-induced tyrosine phosphorylation levels of IR when compared with 


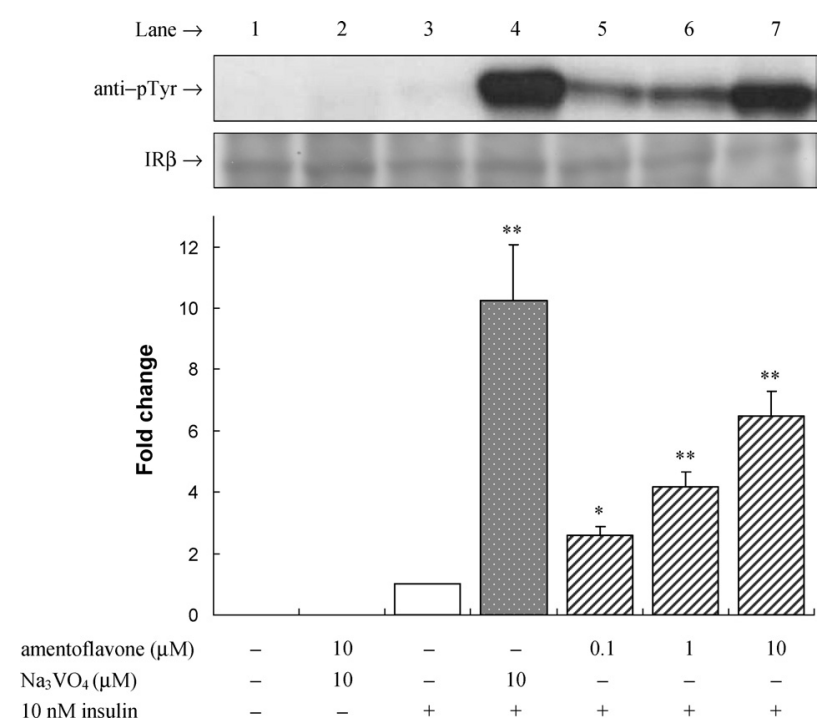

Fig. 3. Effect of Amentoflavone on Tyrosine Phosphorylation of IR in 32D Cells

Subconfluent 32D cells were incubated with a range of concentration of amentoflavone or $\mathrm{Na}_{3} \mathrm{VO}_{4}$ for 60 min followed by 10 -min treatment with $10 \mathrm{~nm}$ insulin. The cell lysates $(80 \mathrm{mg}$ protein) were subjected to SDS-PAGE then transferred to nitrocellulose membrane and followed by western blot with anti-pTyr (G410) antibodies. The bands of IRb were confirmed by western blot with anti-IRb antibodies. The results shown are representative of three independent experiments. Densitometric quantification below the blot shows changes in phosphorylated IR relative to the insulin-treated control (lane 3 ). Each value of fold change represents mean \pm SD. $* p<0.05, * * p<0.01$ compared with control.

control (lane 3). The tyrosine phosphorylation levels of IR increased 2.6-, 4.2-, and 6.4-fold when the cells were treated with $0.1,1$, and $10 \mu \mathrm{M}$ amentoflavone, respectively (Fig. 3). At higher concentrations, the phosphorylation levels of IR actually decreased, which may be caused by nonspecific effects (data not shown). ${ }^{16)}$ This result demonstrates that amentoflavone can enhance the level of insulin-stimulated receptor activation possibly due to its inhibitory effect on PTP1B. Since the phosphorylation of IR is essential for the insulin signaling cascade, our results indicate that amentoflavone may act in the cells to enhance insulin signaling. Although there have been several reports on the biological activities of amentoflavone, ${ }^{9-12)}$ PTP1B-inhibitory activity of amentoflavone and its cellular effect in insulin signaling is reported for the first time in this study.

Acknowledgements This research was supported in part by grants from the Plant Diversity Research Center of 21 st Century Frontier Research Program (PF0320903-00), Global Partnership Program of Korea Foundation for International Cooperation of Science \& Technology, and the KRIBB Research Initiative Program.

\section{REFERENCES AND NOTES}

1) Present address: $M C B I \&$ College of Natural Sciences, Silla University; San 1-1, Gwaebeop-dong, Sasang-gu, Busan 617-736, Korea.

2) Johnson T. O., Ermolieff J., Jirousek M. R., Nat. Rev. Drug Discov., 1, 696-709 (2002).

3) Asante-Appiah E., Kennedy B. P., Am. J. Physiol. Endocrinol. Metab., 284, E663-E670 (2003).

4) Ahmad F., Azevedo J. J., Cortright R., Dohm G., Goldstein B., J. Clin. Invest., 100, 449-458 (1997).

5) Elchebly M., Payette P., Michaliszyn E., Cromlish W., Collins S., Loy A. L., Normandin D., Cheng A., Himms-Hagen J., Chan C. C., Ramachandran C., Gresser M. J., Tremblay M. L., Kennedy B. P., Science, 283, 1544-1548 (1999).

6) Taylor S. D., Hill B., Expert Opin. Investig. Drugs, 13, 199-214 (2004).

7) Kim Y. C., Oh H., Kim B. S., Kang T. H., Ko E. K., Han Y. M., Kim B. Y., Ahn J. S., Planta Med., 71, 87-89 (2005).

8) Bae K., "The Medicinal Plants of Korea," Kyo-Hak Publishing Co., Seoul, 2000.

9) Mora A., Paya M., Rios J. L., Alcaraz M. J., Biochem. Pharmacol., 40, 793-797 (1990).

10) Lin Y. M., Anderson H., Flavin M. T., Pai Y. H., Mata-Greenwood E., Pengsuparp T., Pezzuto J. M., Schinazi R. F., Hughes S. H., Chen F. C., J. Nat. Prod., 60, 884-888 (1997).

11) Lee H. S., Oh W. K., Kim B. Y., Ahn S. C., Kang D. O., Shin D. I., Kim J., Mheen T. I., Ahn J. S., Planta Med., 62, 293-296 (1996).

12) Kang D. G., Yin M. H., Oh H., Lee D. H., Lee H. S., Planta Med., 70, $718-722(2005)$

13) Markham K. R., Sheppard C., Geiger H., Phytochemistry, 26, 33353337 (1987).

14) Oh H., Kim B. S., Bae E. Y., Kim M. S., Kim B. Y., Lee H. B., Kim C. J., Ahn J. S., J. Antibiot., 57, 528-531 (2004).

15) Wiesmann C., Barr K. J., Kung J., Zhu J., Erlanson D. A., Shen W., Fahr B. J., Zhong M., Taylor L., Randal M., McDowell R. S., Hansen S. K., Nat. Struc. Mol. Biol., 11, 730-737 (2004).

16) Xie L., Lee S. Y., Andersen J. N., Waters S., Shen K., Guo X. L., Moller N. P. H., Olefsky J. M., Lawrence D. S., Zhang Z. Y., Biochemistry, 42, 12792-12804 (2003).

17) Suzuki T., Hiroki A., Watanabe T., Yamashita T., Takei I., Umezawa K., J. Biol. Chem., 276, 27511-27518 (2001).

18) Hamaguchi T., Sudo T., Osada H., FEBS Lett., 372, 54-58 (1995).

19) Wang L. M., Myers M. G., Jr., Sun X. J., Aaronson S. A., White M., Pierce J. H., Science, 261, 1591-1594 (1993).

20) Fantus I. G., Ahmad F., Deragon G., Diabetes, 43, 375-383 (1994). 